Check for updates

Madrid

Cite this as: BMJ 2021;375:n2588

http://dx.doi.org/10.1136/bmj.n2588

Published: 22 October 2021

\section{Covid-19: New WHO group to look into pandemic origins is dogged by alleged conflicts of interest}

\author{
Paul D Thacker
}

The World Health Organization has chosen 26 scientists from 700 applicants for a new group to investigate the origins of the covid-19 pandemic, as well as future outbreaks.

WHO plans to appoint members to the new Scientific Advisory Group for the Origins of Novel Pathogens (SAGO) after a two week review to gather public opinion on the proposed choices, which ends on 27 October.

Seven of the current choices (box 1) were part of the WHO international team that travelled to China earlier this year to study the origins of SARS-CoV-2 with Chinese researchers. The team's resulting report downplayed the possibility of a laboratory incident, ${ }^{2}$ and investigators faced complaints about conflicts of interest. Led by the US, several countries, including Australia, Japan, Canada, and the UK, called for a "transparent and independent analysis and evaluation, free from interference and undue influence."3

BoX 1: Proposed SAGO members who were part of WHO's team that met in Wuhan earlier this year to study the origins of SARS-CoV-2 with Chinese researchers

- Vladimir Dedkov, deputy director for research at Pasteur Institute in Russia

- Elmoubasher Farag, senior infectious disease epidemiologist and head of communicable diseases control programmes at Ministry of Public Health in Qatar

- Thea Fischer, professor of virology at University of Copenhagen and head of clinical research at Nordsjaellands Hospital in Denmark

- Marion Koopmans, professor and head of department of viroscience at Erasmus MC

- Hung Nguyen-Viet, co-leader of animal and human health programme at International Livestock Research Institute in Kenya

- John Watson, honorary professor at Faculty of Epidemiology and Population Health, London School of Hygiene and Tropical Medicine, and visiting professor in Research Department of Infection and Population Health at University College London

- Yungui Yang, deputy director at Beijing Institute of Genomics at the Chinese Academy of Sciences

SAGO will advise the WHO Secretariat on emerging pathogens. ${ }^{4}$ Its formation has followed a year and a half of controversy in which researchers investigating the covid-19 origins have been embroiled in various scandals.

A task force commissioned by the Lancet into covid's origins shut down earlier this month over conflicts of interest and ties with Peter Daszak's EcoHealth Alliance, a non-profit group that has funded gain-of-function studies at the Wuhan Institute of Virology. ${ }^{5}$ Early in the pandemic Daszak helped to orchestrate a campaign to label as "conspiracy theorists" people who has asked whether the pandemic started as a laboratory incident. ${ }^{6}$

Critics have expressed concern about some of the people chosen to join SAGO, such as the Thai researcher Supaporn Wacharapluesadee, who is a subcontractor on a US grant for the EcoHealth Alliance.

Richard Ebright, professor of molecular biology at Rutgers University in New Jersey and a biosafety expert, said in a comment he filed with SAGO, "If WHO proceeds with confirming Wacharapluesadee for SAGO membership, then WHO will have failed again-as with its confirmation of EcoHealth Alliance president Peter Daszak to the WHO mission to Wuhan-to meet accepted standards of due diligence and responsibility to the global public."

Filippa Lentzos, codirector of the Centre for Science and Security Studies at King's College London, wrote in an email to The BMJ, "In terms of covid-19, the group would need to have expertise in investigating not just a natural spillover but also a potential lab leak, and I do not believe the group currently has this to the extent necessary. In addition, it appears many of the members do not have an open mind about the origins-an essential quality in any scientific investigative team.”

One proposed member of SAGO is Katherin Summermatter, head of the Biosafety Centre at the Institute for Infectious Diseases at the University of Berne in Switzerland. In at least two interviews last year Summermatter was asked about media reports of a possible lab leak. She responded, "With every new virus, the first hypothesis is that it could have come from a laboratory. However, these speculations are negligible, they are typical conspiracy theories." She told the Swiss newspaper Tages Anzeiger, "I consider it very unlikely, a classic conspiracy theory."

Another proposed SAGO member, Christian Drosten, has also referred to the possibility of a lab leak as a "conspiracy," in a February 2020 essay in the Lancet. ${ }^{7}$ Drosten is head of the Institute of Virology at Berlin's Charité university hospital and is widely respected in Germany as a leading virologist. Drosten did not return The BMJ's repeated requests for comment.

Marion Koopmans, head of the department of viroscience at Erasmus University Medical Centre in the Netherlands and a proposed SAGO member, was untroubled by media reports that some fellow proposed members had dismissed the possibility of a lab leak as a conspiracy theory. In an email to The $B M J$ she wrote, "I am a scientist, trying to stick as 
much as possible to what I consider important: doing what it takes to figure out what happened."

Ebright wrote to The BMJ saying that both Koopmans and Drosten should not serve on SAGO as both had made public comments that had prejudged the investigation before it had even begun. He said that he had filed a detailed comment with SAGO about Summermatter, concluding that she was clearly disqualified for membership on SAGO and should be replaced with a more objective professional in biosafety.

The BMJ sent WHO a detailed query and asked whether applicants were being turned down if they had reasoned that a laboratory incident was a more likely scenario, along with several questions about various proposed members. In an emailed response to The $B M J$ a WHO spokesperson wrote, "We are not commenting on any individual names," but went on to say, “There are two experts with biosecurity expertise: Dr Stuart Blacksell and Dr Katharina Summermatter, second point is that Dr Christian Drosten was not part of the International Team visiting Wuhan earlier this year."

Gary Ruskin, of the non-profit group US Right to Know, which has been investigating academics for conflicts of interest and undisclosed ties to the Wuhan Institute of Virology, said, "If there were a Nobel prize for scientific and political incompetence, surely WHO would be in the running for it."

Drosten and Summermatter prejudged the outcome of the pandemic, Ruskin said, making it perfectly obvious in his view that they should be disqualified. "It is challenging to think of people who are less qualified to serve on the SAGO than Koopmans," he added.

WHO's terms of reference to strengthen public trust and transparency requires that SAGO individuals "must be free of any real, potential, or apparent conflicts of interest."4

1 World Health Organization. Public notice of proposed new Scientific Advisory Group for the Origins of Novel Pathogens (SAGO) members. Oct 2021. https://www.who.int/news-room/articlesdetail/public-notice-and-comment-on-proposed-new-scientific-advisory-group-for-the-originsof-novel-pathogens-(sago)-members.

2 Dyer O. Covid-19: WHO says laboratory escape theory is "extremely unlikely" after mission to China. BMJ 2021;372:n428. doi: 10.1136/bmj.n428 pmid: 33574118

3 Hinshaw D, Page J. US calls for independent study of covid-19 origin. Washington Post. Mar 2021 https://www.wsj.com/articles/countries-call-for-pact-to-improve-response-to-next-pandemic11617100287.

$4 \quad$ World Health Organization. Scientific Advisory Group for the Origins of Novel Pathogens (SAGO) Terms of Reference (20 August 2021). https://cdn.who.int/media/docs/default-source/scientificadvisory-group-on-the-origins-of-novel-pathogens/sago-tors-final-20-aug-21_-(002).pdf.

5 Thacker PD. Covid-19: Lancet investigation into origin of pandemic shuts down over bias risk. BMJ2021;375:n2414. doi: 10.1136/bmj.n2414 pmid: 34598923

6 Thacker PD. The covid-19 lab leak hypothesis: did the media fall victim to a misinformation campaign?BMJ 2021;374:n1656. doi: 10.1136/bmj.n1656 pmid: 34244293

7 Calisher C, Carroll D, Colwell R, etal. Statement in support of the scientists, public health professionals, and medical professionals of China combatting COVID-19. Lancet 2020;395:e42-3 doi: 10.1016/S0140-6736(20)30418-9. pmid: 32087122 